ating one, and if the third cause above is ultimately adopted, it will certainly take a good deal of believing. This is because, if relative motion of masses be the cause, then masses at millions of light-years distance must be supposed to be effective whereas neighbouring masses produce no observable change. The behaviour of a gyrocompass in a submerged submarine is quite unaffected by the large masses of sea-water with various relative motions by which it is surrounded, and yet we must suppose it sensitive to the spiral nebulæ, $\alpha$ Piscium, $\beta$ Leonis, $\gamma$ Cygni, $\delta$ Herculis, $\varepsilon$ Tauri, plus old Ursa Major and all!

To Newton, God was the origin of all things and "by existing always and everywhere, he constitutes duration and space". In Newton's mind the notions of absolute time and absolute space were undoubtedly mixed with pious considerations which no longer enter natural philosophy. Yet if absolute time means time the intervals of which are independent of the motion of any one body in the universe, and absolute space means a referent which is not obtained by taking any one body of the universe as being at rest, then absolute time and space are still the foundation of physical measurement to-day.

${ }^{1}$ Newton, "Principia", 1, 13 (Motte's Translation, 1803).

"Mach, "The Science of Mechanics", 229 (1902).

${ }^{3}$ Einstein, "The Principle of Relativity" (Translated by Saha and Bose, 1920 ).

‘ Eddington, "Space Time and Gravitation", 153 (1920).

\section{A NATIONAL SCHEME FOR HOLIDAY CENTRES}

$I^{\mathrm{N}}$

the broadsheet "Planning for Holidays" (No. 194), Political and Economic Planning directs attention to a problem which may easily become acute, if not dangerous, immediately after the War, unless at least some effort is made to handle it now. The subject of holidays with pay enters into industrial relations, education and the social services, as well as forming an important part of a national health policy.

Only about four million out of about $18 \frac{1}{2}$ million insured workers in Britain in 1937 were entitled to holidays with pay, with about 750,000 salary earners with more than $£ 250$ per annum, but by March 1938 the number of insured workers with paid holidays had risen to about $7 \frac{3}{4}$ millions, and when the Holidays with Pay Act was passed in July 1938, the Government's policy was that, after an interval to allow the extension of holidays by collective agreements, legislation should be passed in 1940 or 1941 making paid holidays compulsory throughout industry. The number of persons actually taking a holiday of one or more weeks away from home in 1937 has been estimated at about 15 millions out of a population of 46 millions. For the immediate post-war period, an estimate of 30 million holiday-makers in the first year after the War and towards 45 millions in successive years is not unreasonable. To meet this demand, holiday accommodation must be increased and an effort made to alter both the custom and the necessity which now concentrate the holiday exodus from the towns in the months of July and August, and especially in the Bank Holiday week. The potential peak of five millions seeking accommodation at one time could, it is estimated, be reduced to between 2 and 4 millions by spreading holidays between May and October.
The staggering of holidays is also important in its bearing on the cost of accommodation, but staggering is primarily a matter for industrial co-operation and for the help of the education authorities in timing school holidays. Moreover, forethought and plan. ning will also be required if the greater demand for holidays is to be prevented from doing irreparable harm to the countryside and seriously interfering with the enjoyment of all. The War, by halting the spoliation of the coast of Britain, for example, has offered an opportunity of checking it permanently.

The urgency of this aspect has been stressed in the second report of the Coastal Preservation Committee, which appeared last October. The preservation of the coast is regarded as an essential item in a national policy for maintaining the beauty of the country; the scientific interest of the coast is an additional reason for its protection. Such preservation cannot be effectively carried out by the local authorities, and the report is in full agreement with the Scott report as to the necessity for immediate national planning, and that coastal preservation should be primarily a responsibility of the State. Coastal planning should include a belt extending sufficiently far inland to preserve the natural features of the general coastal landscape. There should be adequate provision for public access both to and along the shore and coast. Further, the right of the public to the free enjoyment of the foreshore for general recreation should be legally and practically established. Due allowance in planning the coastal belt should be made for probable losses through erosion, and the interference with public access to coastal areas for national defence purposes terminated as soon as military necessity allows.

According to the Planning broadsheet, the immediate post-war problem of holiday accommodation could be met by the conversion into holiday centres of some of the industrial hostels and other suitable war-time Government sites. The former include the Royal Ordnance Factory hostels, with a possible maximum of more than 41,000 places ; the industrial hostels controlled by the National Service Hostels Corporation, with nearly 40,000 projected places in fifty-eight hostels; the temporary hostels outside target towns to house temporarily bombed-out workers and families with more than 50,000 places in seven. teen hostels ; and the three hundred rural hostels for agricultural workers with about 12,000 places. Although much of the accommodation will be in places not well chosen for holidays, more than half may be in suitable districts, and while other claims of comparable social importance may be advanced, it is hoped that a fair proportion will be allotted for holiday centres.

It is estimated that the Service camps have a capacity considerably exceeding that of any other type of war-time accommodation. Some of this will be retained for Service use, but some of the land occupied will be too valuable to retain for camps. Of the rest, much will be unsuitable for holiday requirements, but there should be a considerable useful residue adapted for temporary or permanent holiday use. Another possible source is in the large country houses no longer inhabited by their traditional owners, the expense of upkeep of which may prove progressively onerous. If the State were to acquire them, they could be maintained as people's holiday centres, a house forming a nucleus with annexes in the grounds if necessary. 
The new holiday centres might be placed under the management of a semi-public body of the type of the National Camps Corporation or the National Service Hostels Corporation. Such a National Holiday Centre Corporation would be responsible for maintaining good standards of holiday provision at minimum prices at the centres under its control. Various forms of management might be tried experimentally, including indirect management through non-profit holiday organizations which would be free to run the centres in their own way, subject to inspection and to general conditions as to charges and standards. The Corporation might be assisted by an advisory committee representing the consumers and the experience of voluntary bodies concerned with workers' holidays.

\section{COLONIAL RESEARCH IN THE BRITISH EMPIRE}

$\mathrm{T}$ $\mathrm{HE}$ survey of Colonial research in the British Empire prepared by Dr. Lucy Mair (Agenda for October) is of particular interest at the present moment. Under the Colonial Research Committee appointed in June 1942, a comprehensive survey is at present being made, as the first work of the Committee, of the facilities existing in Great Britain and the Colonial Empire, both for research and for the training of research workers. Pointing out that research in the Colonial field has tended in the past to be directed to the overcoming of practical difficulties that have already been encountered, Dr. Mair emphasizes that the present demand for a planned and consciously directed welfare policy is not a demand for something entirely new, but for more effective measures in the pursuit of aims already accepted. In regard to research by administrative officials, while those responsible for the conduct of policy in the Colonial Empire are fully aware of the need for knowledge of every aspect of the lives of its native populations, such inquiries, often limited in scope by the di ticulty of finding time for them amid the pressure of other work, and carried out by those who have no specialized training in research in the relevant subjects, have not had a scientific value on a level with that of work done by trained specialists devoting their whole time to research.

In social anthropology, the London School of Economics, where B. Malinowski held the chair from 1926 until 1942, is the centre for this work in Great Britain. A great expansion in research was made possible by the Rockefeller Foundation which, after adding social anthropology to the subjects qualifying for its research fellowships, made a generous grant to the International Institute of African Languages and Cultures. The latter body from 1931 until the outbreak of war played a leading part in financing the training of social anthropologists and research by them in Africa. Chairs of social anthropology have been founded at Cape Town and Sydney, and research workers trained at these universities, and also at the Department of African Studies of the University of the Witwatersrand, have undertaken field-work in the adjacent Colonial areas of Africa and the Pacific. While such field-work is in suspense, a special advisory board in Colonial studies constituted in 1941 has undertaken a review for the University of London of the achieve- ments and potentialities of the various social sciences in regard to Colonial research.

At the London School of Economies a Colonial Research Division has been set up to co-ordinate work on the various subjects which have Colonial aspects. Linguistic research in Colonial areas of a most practical kind is the work of the School of Oriental and African Studies (University of London), while the Colonial Department of the University of London Institute of Education has as its primary object the training of teachers for work among Colonial peoples but has also encouraged research on educational problems. The Oxford University Social Studies Research Committee organized in 1938 a co-operative expedition to Kenya, in which two anthropologists, an expert in Colonial administration, an economist and a geographer collaborated. The principal centre at Oxford for sociological research on Colonial questions is now Nuffield College, where a programme of research has been organized including a study of the economic problems of Nigeria and the Gold Coast, a comparative study of the various political institutions which have been developed under British rule in tropical Africa, and a study of the institutions, official and unofficial, through which economic policy is formed and executed.

In addition to the universities, the International Institute of African Languages and Cultures was also in peace-time an important institution for the organization of sociological research in Africa, and the war has prevented the completion of a plan to establish in Northern Rhodesia a Rhodes-Livingstone Memorial Institute as the first centre in Africa itself for the special study of problems arising out of the relations between local peoples and other races. Dr. Mair's survey also includes a brief reference to the London School of Hygiene and Tropical Medicine and the Liverpool School of Tropical Medicine, as well as to other medical research institutes in the Colonial empire where research in tropical medicine, in nutrition and in other health matters is carried out.

There are numerous institutions in the Colonies and in Great Britain which are concerned with agricultural and veterinary research and assist Colonial research workers with information and technical advice. Fishery departments have made surveys of local resources in Palestine and in West Africa, while in Malaya the Fisheries Department has concentrated its attention on raising the efficiency of this native industry. In the Colonial empire the most extensive forestry research has been done in Malaya by a well-equipped Forest Research Institute. The principal centre for forest research in Great Britain is the Imperial Forestry Institute at the University of Oxford, while research on the utilization of forest products is carried out by the Forest Products Research Laboratory, Princes Risborough, and the Colonial Forest Resources Development Department. A considerable amount of research has been carried out on the mineral resources of most Colonies by the geological departments, as well as by mining and oil companies, and this work has the assistance of the Mineral Resources Department of the Imperial Institute. At the present time, research on technical subjects has run far ahead of the study of social and economic problems, and Dr. Mair suggests that the disproportion may be corrected by the influence of the new Colonial Research Committee, on which both the social and the natural sciences are represented. 